\title{
ІНФОРМАЦІЙНО-АНАЛІТИЧНА СИСТЕМА СУПРОВОДУ ФІНАНСОВО-КРЕДИТНОЇ ДІЯЛЬНОСТІ: МОДЕЛІ БАЗОВИХ ТА ВАЛЮТНИХ КРЕДИТІВ
}

\author{
Марецька E.
}

\begin{abstract}
Анотація: Запропоновано математичні моделі консолідаџіï кредитів, щзо сплачуються y повних внесках. Розроблені моделі враховують різноманітні способи нарахування процентів: простий чи складний, постійну чи змінну процентні ставки. Створений математичний апарат дає можливість порівнювати кошти кредитів, знаходити оптимальні умови надання кредитів.
\end{abstract}

Ключові слова: інформачійно-аналітична система, кредит, повний внесок, математична модель

\section{1. ВСТУП.}

Характерними рисами ряду фінансових процесів єпевні послідовностіплатежів (наприклад, сплачування кредитів, ощадних чи пенсійних внесків, тощо), тобто дискретизація цих платежів в часі, а також збільшення розмірів внесків 3 часом, що відображається за допомогою певних формул нарахування процентів чи дисконтування $[1,2]$. В ринкових умовах деякі платежі не $є$ гарантованими, а це означає, що є певний ризик недотримання графіку вчасного повернення кредиту чи несплати відповідного внеску.

Зустрічаються випадки, коли клієнт сплачує декілька кредитів (здебільшого два-три) взятих в різні часи у одного і того самого кредитора. Будь-яка затримка сплати клієнтом чергового внеску вимагає оперативного перегляду подальшого графіку сплати кредитів [2]. Тоді, як з боку клієнта, так і з боку кредитора може ініціюватися процедура консолідації (об'єднання) всіх сплачуваних кредитів в один з дещо подовженим терміном сплати. При цьому потрібно врахувати уже сплачені частини кредитів та визначити графік і розміри внесків для сплати нового (“консолідованого”) кредиту.

Математичні моделі складних процесів консолідації кредитів, про які йдеться в цій статті, базуються на принципі еквівалентності капіталу. Цей принцип дає можливість порівнювати два чи більше капіталів, що відносяться до різних моментів часу, враховувати як минулий, так і майбутній (прогнозований) стани фінансового ринку, різноманітні способи нарахування процентів, індексації чи валоризації внесків. Такі засоби математичного моделювання дають також можливість визначити оптимальні терміни консолідації, які мінімізують клієнтові загальний кошт взятих кредитів.

\section{2. ПОСТАНОВКА ЗАДАЧІ.}

Нехай один клієнт сплачує $M$ кредитів одному кредиторові, причому сплата здійснюється виключно у повних внесках, тобто у внесках, в яких не вирізняють окремо відсоткову [3] чи капіталову [4] (породжену капіталом) частини. Для кожного із кредитів заданими $є$ такі параметри: $t_{b_{m}}$ s час оформлення (момент початку дії) $m$-го кредиту, $m=1, \ldots, M$, де $b_{m} \epsilon$ порядковим номером часової дискрети, що відповідає початкові дії $m$-го кредиту; $t_{0} \mathrm{~s}$ початок дії кредиту, оформленого найшвидше, тобто $t_{0}=\min _{m=1, \ldots, M} t_{b_{m}} ; P_{m b_{m}}$ s квота (наданий капітал) $m$-го кредиту; $N_{m}$ s число внесків $m$-го кредиту. Відповідно, для консолідованого кредиту заданими $є: t_{k} \mathrm{~s}$ момент часу, в який здійснюється консолідація всіх кредитів в один; $N$ s число внесків консолідованого кредиту. Вважаємо, що відомими є також розміри процентних ставок, а також коефіцієнти індексації чи валоризації. Задача полягає в тому, що за різних умов нарахування процентів необхідно знайти розміри внесків всіх кредитів перед об'єднанням, розміри всіх технічних кредитів в момент консолідації, розміри внесків консолідованого кредиту, а також шляхом математичного моделювання знайти умови надання кредиту, які забезпечують мінімальний 3 точки зору клієнта сумарний кошт всіх кредитів. 


\section{3. МАТЕМАТИЧНІ МОДЕЛІ КРЕДИТІВ ПЕРЕД КОНСОЛІДАЦІЄЮ.}

Нехай період дискретизації фінансового процесу є постійним і дискретні терміни сплати внесків співпадають ( $n$-й термін сплати внеску відноситься до кінця $n$-го проміжку часу, причому, якщо $t_{n} \in$ терміном сплати внеску одного $з$ кредитів, то він водночас $\epsilon$ терміном сплати внесків всіх інших кредитів, які діють на цей час. Моделювання процесу консолідації кредитів розглянемо у трьох фазах: визначення розмірів внесків всіх кредитів, розрахунок розмірів всіх технічних кредитів в момент консолідації, визначення розмірів внесків консолідованого кредиту.

Нехай: $R_{m n} \mathrm{~s} n$-й повний внесок $m$-го кредиту (внесок в момент $t=t_{n}$ ); $C_{m i} \mathrm{~s}$ коефіцієнт нарахування процентів $m$-го кредиту за $i-$ й термін, причому залежить він виключно від макроекономічних показників (рівня інфляції) та часу, за який здійснюється нарахування процентів. Для знаходження розмірів внесків всіх кредитів перед консолідацією записуємо рівняння еквівалентності капіталу у вигляді

$$
P_{m b_{n}} C_{m b_{n}}=\sum_{n=b_{m}+1}^{b_{m}+N_{m}} R_{m n} C_{m n}, \quad m=1, \ldots, M,
$$

а також вирази, які відображають індексацію чи валоризацію внесків кредиту

$$
\begin{aligned}
& R_{m n}=R_{m, b_{m}+1}\left(1+j_{m}\right)^{n-b_{m}-1}, \quad n=b_{m}+2, \ldots, b_{m}+N_{m} ; \\
& m=1, \ldots, M, \\
& R_{m n}=R_{m, b_{m}+1}+\left(n-b_{m}-1\right) \Delta_{m}, \quad n=b_{m}+2, \ldots, b_{m}+N_{m} ; \\
& m=1, \ldots, M,
\end{aligned}
$$

де $j_{m}$ s ставка індексації $m$-го кредиту, $\Delta_{m} \mathrm{~s}$ його квота валоризації. У випадку індексації внески утворюють геометричну прогресію, а у випадку валоризації $\mathrm{s}$ арифметичну.

Використовуючи вирази (2) чи (3) систему $M$ рівнянь (1) можна спочатку розв'язати відносно розмірів перших внесків $R_{m, b_{m}+1}$, $m=1, \ldots, M$, а потім знайти розміри всіх інших повних внесків $R_{m n}, \quad n=b_{m}+2, \ldots, b_{m}+N_{m}$, $m=1, \ldots, M$. Величини коефіцієнтів нарахування процентів $C_{m i}$ вважаємо при цьому відомими, формули для їх знаходження залежать від способу нарахування процентів. Рівняння (1), отримані для кожного кредиту на основі принципу еквівалентності капіталу, зручно записувати для вузла дискретизації, що відповідає останньому внескові сплати цього кредиту, при цьому $C_{m, b_{m}+N_{m}}=1$.

\section{4. МОДЕЛЬ КОНСОЛІДАЦІї.}

В термін $t=t_{k}$ здійснюємо консолідацію (об’єднання) всіх кредитів в один. Цей термін повинен задовольняти умову

$$
\max _{m=1, \ldots, M}\left(t_{b_{m}}\right)<t_{k}<\min _{m=1, \ldots, M}\left(t_{b_{m}+N_{m}}\right)
$$

в цей термін не здійснюється сплата поточних внесків. Розглядатимемо однорідну модель консолідації кредиту, тобто модель, в якій тип внесків та способи нарахування процентів не змінюються після консолідації. На практиці зазвичай виконується умова

$$
t_{k+N} \geq \max _{m=1, \ldots, M}\left(t_{b_{m}+N_{m}}\right)
$$

тобто термін завершення сплати об'єднаного кредиту $\epsilon$, як правило, пізнішим від терміну завершення сплати найпізнішого неконсолідованого кредиту.

При здійсненні консолідації кредитів насамперед виконують конверсію кожного з кредитів на спільний термін $t=t_{k}$. Така конверсія полягає у визначенні квот $P_{m k}$ одноразової сплати ще не сплачених внесків всіх кредитів. Ці квоти $P_{m k}$ називають технічними кредитами (для $m$-го кредиту стосовно терміну $t=t_{k}$ ). Розміри технічних кредитів визначаємо шляхом дисконтування всіх не сплачених внесків на термін консолідації

$$
P_{m k}=R_{m k}+\sum_{n=k+1}^{b_{m}+N_{m}} R_{m n} / D_{m n},
$$

де $\mathrm{s}$ коефіцієнти дисконтування $m$-го кредиту за $n$-й термін, які залежать від рівня інфляції та часу дисконтування.

Після конверсії всіх кредитів до сплати в термін $t=t_{k}$ залишаються $M$ технічних кредитів $P_{m k}$, які можна замінити одним консолідованим кредитом

$$
P_{k}=\sum_{m=1}^{M} P_{m k} .
$$


Цей кредит може бути наданий на інших умовах (інші розміри процентних ставок; термін сплати внесків до $\left.t=t_{k+N}\right)$.

\section{5. ВНЕСКИ КОНСОЛІДОВАНОГО КРЕДИТУ.}

Величини повних внесків консолідованого кредиту визначаємо аналогічно як і розміри внесків всіх кредитів перед консолідацією, тобто на основі принципу еквівалентності капіталу, який у цьому випадку записуємо у вигляді

$$
P_{k} C_{k}=\sum_{n=k+1}^{k+N} R_{n} C_{n},
$$

де $C_{n}, n=k, \ldots, k+N$ s віднесені до консолідованого кредиту коефіцієнти нарахування процентів за $n$-й термін, які залежить рівня інфляції та часу, за який здійснюється нарахування процентів. Величини коефіцієнтів нарахування процентів $C_{n}$ вважаємо при цьому відомими, формули для їх знаходження залежать від спо собу нарахування процентів.

Записуємо також вирази, які відображають індексацію чи валоризацію внесків консолідованого кредиту

$$
\begin{aligned}
& R_{n}=R_{k+1}(1+j)^{n-k-1}, \quad n=k+2, \ldots, k+N ; \quad \text { (7) } \\
& R_{n}=R_{k+1}+(n-k-1) \Delta, \quad n=k+2, \ldots, k+N,
\end{aligned}
$$

де $j \mathrm{~s}$ ставка індексації внесків, $\Delta \mathrm{s}$ ї квота валоризації.

Враховуючи вирази (7) чи (8) рівняння (6) розв'язують відносно розміру першого повного внеску $R_{k+1}$, а потім знаходять розміри всіх інших повних внесків $R_{n}, n=k+2, \ldots, k+N$. Рівняння (6), яке відображає принцип еквівалентності капіталу, записане для вузла дискретизації, що відповідає останньому внескові сплати консолідованого кредиту, при цьому звичайно $C_{k+N}=1$.

\section{6. КОШТИ КРЕДИТІВ.}

Для випадку короткотермінових кредитів, як правило, використовують просте нарахування процентів з постійною чи змінною процентними ставками. Кошт такого кредиту можна трак- тувати як різницю між сумою внесків, які віддано кредиторові, та квотою цього кредиту. У випадку довготермінового кредиту (3 часом сплати понад один рік) використовують складне нарахування процентів 3 постійною чи змінною процентною ставкою в залежності від рівня інфляції та інших макроекономічних показників.

Нехай $Q_{m}, m=1, \ldots, M$ s кошти всіх кредитів (без врахування консолідачіï). Визначаємо иі кошти за допомогою формули $Q_{m}=\sum_{m=1}^{N_{m}} R_{m n}-P_{m b_{m}}$. Тоді повний кошт всіх кредитів знаходимо як суму коштів окремих кредитів $\quad y \quad$ вигляд $i \quad Q_{\Sigma}=\sum_{m=1}^{M} Q_{m}$. Натомість, загальний кошт всіх М кредитів з консолідацією (позначимо його через Q) визначаємо як різничю між сумою всіх внесків, сплачених кредиторові (як перед консолідацією, так і після неї), та сумою квот (наданих капіталів) всіх кредитів, тобто

$$
Q=\sum_{m=1}^{M} \sum_{n=b_{m}+1}^{k-1} R_{m n}+\sum_{n=k+1}^{k+N} R_{n}-\sum_{m=1}^{M} P_{m b_{m}} .
$$

Перший доданок цієї формули відображає суму внесків всіх кредитів перед консолідацією, другий доданок s суму внесків консолідованого кредиту, а третій доданок s суму квот наданих кредитів.

\section{7. МОДЕЛЬ ПРОСТОГО НАРАХУВАННЯ ПРОЦЕНТІВ.}

Розглянемо чотири варіанти математичних моделей консолідації кредитів сплачуваних у повних внесках при різноманітних способах нарахування процентів, а саме, просте та складне нарахування процентів, постійна або зміна процентна ставка. У випадку простого нарахування процентів 3 постійною ставкою для кожного $з$ кредитів характерним є свій постійний розмір процентної ставки

$$
\begin{aligned}
& s_{m}=\text { const }, \forall n=b_{m}, \ldots, b_{m}+N_{m}, \\
& m=1, \ldots, M . \text { При цьому коефіцієнти нараху- }
\end{aligned}
$$
вання процентів $C_{m n}$ знаходимо за допомогою формули $C_{m n}=1+s_{m}\left(N_{m}-n\right)$. Для кожного із кредитів перед консолідацією можна записати рівняння еквівалентності капіталу, віднесене до кінця терміну сплати цього кредиту, а саме 


$$
\begin{aligned}
& P_{m b_{m}}\left(1+s_{m} N_{m}\right)=\sum_{n=b_{m}+1}^{b_{m}+N_{m}} R_{m n}\left[1+s_{m}\left(b_{m}+N_{m}-n\right)\right], \\
& m=1, \ldots, M .
\end{aligned}
$$

Використовуючи систему рівнянь (10) 3 врахуванням відповідних виразів (2) чи (3) для індексації чи валоризації внесків отримуємо розміри всіх внесків $R_{m n}$ неконсолідованих кредитів. Величини технічних кредитів перед консолідацією (на момент $t=t_{k}$ ) визначаємо шляхом дисконтування всіх несплачених внесків на момент консолідації

$$
\begin{aligned}
& P_{m k}=R_{m k}+\sum_{n=k+1}^{b_{m}+N_{m}} \frac{R_{m n}}{1+S_{m}(n-k)}, \\
& m=1, \ldots, M,
\end{aligned}
$$

причому вираз у знаменнику є коефіцієнтом дисконтування $D_{m n} m$-го кредиту за $n$-й термін.

На основі сумарного технічного кредиту (формула (5)) записуємо рівняння еквівалентності капіталу для консолідованого кредиту

$$
P_{k}(1+s N)=\sum_{n=k+1}^{k+N} R_{n}[1+s(k+N-n)],
$$

причому процентна ставка $s \in$ постійною для всіх термінів сплати цього кредиту, тобто $s=$ const $, \forall n=k+1, \ldots, k+N$. На основі останнього рівняння з врахуванням виразів (7) чи (8), які відображають індексацію чи валоризацію внесків, знаходимо розміри всіх повних внесків $R_{n}, n=k+1, \ldots, N$ консолідованого кредиту.

У випадку простого нарахування процентів із змінною ставкою розміри процентних ставок $\epsilon$ різними для всіх термінів сплати внесків. Позначимо через $s_{m n}$ процентну ставку для $m-$ го кредиту за $n$-й термін $\left(s_{m n} \neq\right.$ const, $\left.\forall n=b_{m}, \ldots, b_{m}+N_{m}, \quad m=1, \ldots, M\right)$. При цьому коефіцієнти нарахування процентів $C_{m n}$ знаходимо за допомогою формули

$$
C_{m n}=\left\{\begin{array}{cc}
1, & n=b_{m}+N_{m} ; \\
1+\sum_{i=n}^{b_{m}+N_{m}-1} s_{m, i+1}, & n<b_{m}+N_{m} .
\end{array}\right.
$$

Рівняння еквівалентності капіталу для кожного $з$ кредитів перед консолідацією, віднесене до кінця терміну сплати цього кредиту, можна записати у вигляді

$$
\begin{aligned}
& P_{m b_{m}}\left(1+\sum_{n=b_{m}}^{b_{n}+N_{m}} s_{m n}\right)=\sum_{n=b_{m}+1}^{b_{m}+N_{m}-1} R_{m n}\left(1+\sum_{i=n+1}^{b_{m}+N_{m}} s_{m i}\right)+R_{m N_{m}}, \\
& m=1, \ldots, M .
\end{aligned}
$$

На основі останньої системи рівнянь 3 врахуванням відповідних виразів для індексації чи валоризації внесків отримуємо розміри внесків $R_{m n}$ неконсолідованих кредитів. Величини технічних кредитів визначаємо шляхом дисконтування всіх несплачених внесків

$$
\begin{aligned}
& P_{m k}=R_{m k}+\sum_{n=k+1}^{b_{m}+N_{m}} \frac{R_{m n}}{1+\sum_{i=n}^{b_{m}+N_{m}} S_{m i}}, \\
& m=1, \ldots, M .
\end{aligned}
$$

Причому вираз у знаменнику є коефіцієнтом дисконтування $D_{m n}$, для якого справджується рекурентне співвідношення

$$
\begin{aligned}
& D_{m k}=1, D_{m n}=D_{m, n-1}+s_{m n}, \\
& \forall n=k+1, k+2, \ldots, k+N_{m} .
\end{aligned}
$$

Рівняння еквівалентності капіталу для консолідованого кредиту отримуємо на основі сумарного технічного кредиту $P_{k}=\sum_{m=1}^{M} P_{m k}$ у вигляді

$$
P_{k}\left(1+\sum_{n=k}^{k+N} s_{n}\right)=\sum_{n=k+1}^{k+N-1} R_{n}\left(1+\sum_{i=n+1}^{k+N} s_{i}\right)+R_{k+N},
$$

де $S_{n}$ s процентна ставка для консолідованого кредиту за $n$-й термін, причому $s_{n} \neq$ const $, \quad \forall n=k+1, \ldots, k+N$. Останнє рівняння з врахування відповідних виразів для індексації (7) чи валоризації (8) внесків консолідованого кредиту дає можливість визначити розміри всіх повних внесків цього кредиту.

\section{8. МОДЕЛЬ СКЛАДНОГО НАРАХУВАННЯ ПРОЦЕНТІВ.}

У випадку складного нарахування процентів 3 постійною ставкою для кожного 3 кредитів характерним є свій розмір процентної ставки

$$
\begin{aligned}
& s_{m}=\text { const }, \\
& \forall n=b_{m}, \ldots, b_{m}+N_{m},
\end{aligned}
$$


$m=1, \ldots, M$. Коефіцієнти нарахування процентів $C_{m n}$ знаходимо за допомогою формули $C_{m n}=\left(1+s_{m}\right)^{N_{m}-n}$. Для кожного із кредитів перед консолідацією можна записати рівняння еквівалентності капіталу

$$
\begin{aligned}
& P_{m b_{m}}\left(1+s_{m}\right)^{N_{m}}=\sum_{n=b_{m}+1}^{b_{m}+N_{m}} R_{m n}\left(1+s_{m}\right)^{b_{m}+N_{m}-n}, \\
& m=1, \ldots, M .
\end{aligned}
$$

3 системи рівнянь (11) з врахуванням відповідних виразів для індексації чи валоризації внесків отримуємо розміри всіх внесків $R_{m n}$ неконсолідованих кредитів. Величини технічних кредитів перед консолідацією (для $t=t_{k}$ ) визначаємо шляхом дисконтування всіх несплачених внесків на момент консолідації

$$
\begin{aligned}
& P_{m k}=\sum_{n=k}^{b_{m}+N_{m}} R_{m} /\left(1+s_{m}\right)^{n-k}, \\
& m=1, \ldots, M, \text { причому вираз у знаменнику є }
\end{aligned}
$$

коефіцієнтом дисконтування $D_{m n}$, для якого має місце рекурентне співвідношення $D_{m k}=1$,

$$
\begin{aligned}
& D_{m n}=D_{m, n-1}\left(1+s_{m}\right), \\
& \forall n=k+1, k+2, \ldots, k+N_{m} .
\end{aligned}
$$

На основі сумарного технічного кредиту, отриманого за формулою (5), записуємо рівняння еквівалентності капіталу для консолідованого кредиту

$$
P_{k}(1+s)^{N}=\sum_{n=k+1}^{k+N} R_{n}(1+s)^{k+N-n},
$$

причому процентна ставка $s$ єпостійною для всіх термінів сплати цього кредиту, тобто $s=$ const $, \forall n=k+1, \ldots, k+N$. На основі цього рівняння з врахуванням виразів (7) чи (8), які відображають індексацію чи валоризацію внесків, знаходимо розміри всіх повних внесків $R_{n}, n=k+1, \ldots, N$ консолідованого кредиту.

Для випадку довготермінових кредитів зручною в практичному відношенні $є$ так звана ефективна процентна ставка. Позначаємо ii через $\varepsilon$ і знаходимо шляхом розв'язування нелінійного алгебраїчного рівняння

$\sum_{m=1}^{M} P_{m b_{m}}(1+\varepsilon)^{k+N-b_{m}}=\sum_{m=1}^{M} \sum_{n=b_{m}+1}^{k-1} R_{m n}(1+\varepsilon)^{k+N-n}+\sum_{n=k+1}^{k+N} R_{n}(1+\varepsilon)^{k+N-n}$,

сформованого на основі принципу еквівалентності капіталу для терміну $t=t_{k+N}$. Ліва частина цього рівняння відповідає квотам неконсолідованих кредитів, перший доданок правої частини відображає уже сплачені до моменту консолідації внески, а другий доданок $\mathrm{s}$ повні внески консолідованого кредиту.

У випадку складного нарахування процентів із змінною ставкою розміри процентних ставок $\epsilon$ різними для всіхтермінів сплати внесків. Якщо $s_{m n}$ - процентна ставку для $m-$-го кредиту за $n$-й термін

$$
\begin{aligned}
& \left(s_{m n} \neq \text { const },\right. \\
& \forall n=b_{m}, \ldots, b_{m}+N_{m}, \\
& m=1, \ldots, M), \text { то коефіцієнти нарахування }
\end{aligned}
$$
процентів $C_{m n}$ знаходимо за допомогою формули

$$
C_{m n}=\left\{\begin{array}{cc}
1, & n=b_{m}+N_{m} ; \\
\prod_{i=n}^{b_{m}+N_{m}-1}\left(1+S_{m, i+1}\right), & n<b_{m}+N_{m} .
\end{array}\right.
$$

Рівняння еквівалентності капіталу для кожного 3 кредитів перед консолідацією, віднесене до кінця терміну сплати цього кредиту, можна записати у вигляді

$$
\begin{aligned}
& P_{m b_{m}} \prod_{n=b_{m}+1}^{b_{m}+N_{m}}\left(1+s_{m n}\right)=\sum_{n=b_{m}+1}^{b_{m}+N_{m}-1}\left[R_{m n} \cdot \prod_{i=n+1}^{b_{m}+N_{m}}\left(1+s_{m i}\right)\right]+R_{m N_{m}}, \\
& m=1, \ldots, M .
\end{aligned}
$$

На основі цієї системи рівнянь з врахуванням відповідних виразів для індексації чи валоризації внесків отримуємо розміри внесків $R_{m n}$ неконсолідованих кредитів. Величини технічних кредитів визначаємо шляхом дисконтування всіх несплачених внесків

$$
\begin{aligned}
& P_{m k}=R_{m k}+\sum_{n=k+1}^{b_{m}+N_{m}} \frac{R_{m n}}{\prod_{i=n}^{b_{m}+N_{m}}\left(1+S_{m i}\right)}, \\
& m=1, \ldots, M .
\end{aligned}
$$

Вираз у знаменнику є коефіцієнтом дисконтування $D_{m n} m$-го кредиту за $n$-й термін, для якого справджується рекурентне співвідношення $D_{m k}=1, \quad D_{m n}=D_{m, n-1}\left(1+s_{m n}\right)$, $\forall n=k+1, k+2, \ldots, \quad k+N_{m}$.

Рівняння еквівалентності капіталу для консолідованого кредиту отримуємо на основі сумарного технічного кредиту $P_{k}=\sum_{m=1}^{M} P_{m k}$ у вигляді 


$$
P_{k} \cdot \prod_{n=k+1}^{k+N}\left(1+s_{n}\right)=\sum_{n=k+1}^{k+N-1}\left[R_{n} \cdot \prod_{i=n+1}^{k+N}\left(1+s_{n}\right)\right]+R_{k+N}
$$

де $s_{n}$ s процентна ставка для консолідованого кредиту в $n$-му терміні, причому $s_{n} \neq$ const, $\forall n=k+1, \ldots, k+N$. Останнє рівняння з врахування відповідних виразів для індексації (7) чи валоризації (8) внесків консолідованого кредиту дає можливість визначити розміри всіх повних внесків $R_{n}$ цього кредиту.

\section{9. МАТЕМАТИЧНІ МОДЕЛІ ВАЛЮТНИХ КРЕДИТІВ.}

Кредит, наданий в іноземній валюті, повинен бути повернутий також у валюті. Це означає, що на сплату відповідних внесків необхідно закупити валюту у відповідності з певним курсом. Якщо в процесі сплати кредиту курс валюти не змінюється, то реальна процентна ставка валютного кредиту дорівнює номінальній процентній ставці. В такому випадку валютний кредит є дешевшим від кредиту в національній валюті. Натомість, якщо в процесі сплати кредиту курс валюти зростає, то клієнт витрачає більше коштів ніж передбачалося початково. В такому випадку реальна процентна ставка може бути більшою ніж номінальна. В граничному випадку реальна процентна ставка валютного кредиту може бути навіть вищою від номінальної процентної ставки кредиту в національній валюті (тоді валютний кредит є невигідним).

Математичні моделі валютних кредитів базуються на принципі еквівалентності капіталу та відображають три фази кредитного процесу: визначення внесків кредиту, конверсія кредиту та консолідація кредиту. Конверсія кредиту означає повторне визначення внесків частково сплаченого кредиту. Причинами конверсії можуть бути: несплата поточного внеску, сплата коштів більших ніж внесок, зміна процентної ставки, терміну сплати, курсу валюти, тощо. Консолідація кредитів має місце у випадку повторного визначення графіку сплати кількох частково сплачених кредитів одному і тому самому кредиторові.

Для побудови математичних моделей процесу сплати кредитів розглянемо два етапи, які охоплюють базовий та валютний кредити. Вважатимемо, що $P_{0}$ - квота базового кредиту, $N$ - число внесків, $j$ - розмір індексації повних внесків $R_{n}, \Delta$ - ї квота валоризації. Необхідно визначити повні внески $R_{n}$ для $t_{n}, n=1, \ldots, N$. Ці внески визначаємо на підставі рівняння еквівалентності капіталу та відповідних виразів для індексації чи валоризації. Рівняння еквівалентності капіталу записуємо у вигляді

$$
\begin{aligned}
& P_{0} C_{0}=\sum_{n=1}^{N} R_{n} C_{n}, \\
& \text { де } C_{n}, n=0, \ldots, N \text { - коефіцієнти нарахування }
\end{aligned}
$$
процентів кредиту за $n$-й термін. Вирази, які відображають індексацію чи валоризацію, мають вигляд аналогічний (2) та (3), у випадку індексації внески утворюють геометричну прогресію, а у випадку валоризації - арифметичну.3 врахуванням виразів (2) чи (3) рівняння еквівалентності капіталу можна спочатку розв'язати відносно розміру першого внеску $R_{1}$, а потім знайти розміри всіх інших повних внесків $R_{n}, n=2, \ldots, N$. Величини коефіцієнтів нарахування процентів вважаємо при цьому відомими.

Валютний кредит $W_{0}$ повинен бути сплачений у повних внесках $R_{n}^{(w)}, n=1, \ldots, N$. У випадку браку валюти для сплати внесків $R_{n}^{(w)}$ необхідно закупити валюту за курсом $q_{n}$. Отже, отриманий кредит $W_{0}$ може бути перерахований за курсом $q_{0}$ у відповідний кредит у національній валюті $V_{0}$. Аналогічно, повні валютні внески $R_{n}^{(w)}$ можна перерахувати на відповідні внески в національній валюті $Z_{n}$. При цьому повстає питання - яка $є$ реальна еквівалентна процентна ставка валютного кредиту. Кредит в національній валюті можна отримати із процентною ставкою $s$, натомість кредит валютний - із процентною ставкою $S^{(w)}$, причому на практиці виконується нерівність $s^{(w)}<s$.

Коли величина зміни курсу задовольняє умову $\Delta q>0$, розміри еквівалентних внесків у національній валюті ростуть. Це може спричинити до то, що еквівалентна процентна ставка валютного кредиту $y$ може задовольняти нерівність $y>s$. В цьому випадку валютний кредит є більш коштовним у порівнянні 3 кредитом у національній валюті. Нехай для 
валютного кредиту заданими $є: W_{0}$ - квота кредиту, $N$ - число внесків, $j^{(w)}$ - розмір індексації повних внесків $R_{n}^{(w)}, \Delta^{(w)}$ - їх квота валоризації. Необхідно визначити повні внески $R_{n}^{(w)}$, які потрібно сплатити в терміни $t_{n}$, $n=1, \ldots, N$.

Повні валютні внески задовольняють рівняння еквівалентності капіталу у вигляді $W_{0} C_{0}^{(w)}=\sum_{n=1}^{N} R_{n}^{(w)} C_{n}^{(w)}$, де $C_{n}^{(w)}, n=0, \ldots, N$ коефіцієнти нарахування процентів для валютного кредиту за $n$-й термін. Вирази, які відображають індексацію чи валоризацію внесків, мають, відповідно, вигляд

$$
R_{n}^{(w)}=R_{1}^{(w)}\left(1+j^{(w)}\right)^{n-1}
$$

та $R_{n}^{(w)}=R_{1}^{(w)}+(n-1) \Delta^{(w)}$. На основі цих рівнянь та виразів можливість обчислити розміри всіх повних валютних внесків $R_{n}^{(w)}$, $n=1, \ldots, N$. Оскільки відомими є розміри всіх курсів валют $q_{n}, n=0, \ldots, N$, то можна записати вирази для еквівалентних повних внесків у національній валюті: для повного кредиту $V_{0}=W_{0} q_{0}$; для повних внесків - $Z_{n}=R_{n}^{(w)} q_{n}$, $n=1, \ldots, N$.

На основі відомого розміру кредиту $V_{0}$, а також розмірів еквівалентних повних внесків $Z_{n}$, $n=1, \ldots, N$ знаходимо еквівалентну процентну ставку $y$ для довільних курсів валют $q_{n}$, $n=1, \ldots, N$. Приймаючи, що від сплати одного внеску до іншого курс валюти змінюється на $\Delta q$ можна отримати залежність $y=f\left(q_{0}, \Delta q\right)$. 3 iї допомогою можна визначити, при якій зміні курсу валют валютний кредит стане невигідним.

\section{0. ПОСТІЙНА ПРОЦЕНТНА СТАВКА ДЛЯ ВАЛЮТНИХ КРЕДИТІВ.}

Розглянемо чотири варіанти математичних моделей валютних кредитів сплачуваних у повних внесках при різноманітних способах нарахування процентів, а саме, просте та складне нарахування процентів, постійна або змінна процентні ставки. У випадку простого нарахування процентів із постійною ставкою розмір процентної ставки задовольняє умову $s=$ const $, \forall n=0, \ldots, N$. При цьому коефіцієнти нарахування процентів $C_{n}$ знаходимо за допомогою формули $C_{n}=1+s(N-n)$. Для базового кредиту у національній валюті можна записати рівняння еквівалентності капіталу, віднесене до кінця терміну сплати цього кредиту, у вигляді $P_{0}(1+s N)=\sum_{n=1}^{N} R_{n}[1+s(N-n)]$ Це рівняння разом з відповідними виразами (2) та (3) для індексації чи валоризації дають можливість визначити розміри всіх повних внесків $R_{n}$.

Повні внески валютного кредиту задовольняють рівняння еквівалентності капіталу

$$
W_{0}\left(1+s^{(w)} N\right)=\sum_{n=1}^{N} R_{n}^{(w)}\left[1+s^{(w)}(N-n)\right],
$$

на основі якого, а також з врахуванням виразів індексації чи валоризації, знаходимо розміри цих внесків. Еквівалентну процентну ставку валютного кредиту знаходимо як розв'язок рівняння $V_{0}(1+y N)=\sum_{n=1}^{N} Z_{n}[1+y(N-n)]$.

У випадку складного нарахування процентів iз постійною ставкою коефіцієнти $C_{n}$ знаходимо за допомогою формули $C_{n}=(1+s)^{N-n}$. Для базового кредиту в національній валюті на основі рівняння еквівалентності капіталу $P_{0}(1+s)^{N}=\sum_{n=1}^{N} R_{n}(1+s)^{N_{m}-n}, 3$ врахуванням відповідних виразів для індексації або валоризації внесків, отримуємо розміри всіх повних внесків $R_{n}$ базового кредиту. Повні внески $R_{n}^{(w)}$ валютного кредиту задовольняють рівняння еквівалентності капіталу

$$
W_{0}\left(1+s^{(w)}\right)^{N}=\sum_{n=1}^{N} R_{n}^{(w)}\left(1+s^{(w)}\right)^{N_{m}-n},
$$

на основі якого, а також з врахуванням виразів (7) та (8), знаходимо розміри цих внесків. Еквівалентну процентну ставку валютного кредиту знаходимо як розв'язок рівняння $V_{0}(1+y)^{N}=\sum_{n=1}^{N} Z_{n}(1+y)^{N-n}$.

\section{1. ЗМІННА ПРОЦЕНТНА СТАВКА ДЛЯ ВАЛЮТНИХ КРЕДИТІВ.}

В цьому випадку розміри процентних ставок $\epsilon$ різними для всіх термінів сплати внесків. 
Позначимо через $s_{n}$ процентну ставку (національна валюта) за $n$-й термін ( $s_{n} \neq$ const, $\forall n=0, \ldots, N)$. При цьому рівняння еквівалентності капіталу для базового кредиту у національній валюті, віднесене до кінця терміну сплати цього кредиту, можна записати у вигляді

$$
P_{0}\left(1+\sum_{n=0}^{N} s_{n}\right)=\sum_{n=1}^{N-1} R_{n}\left(1+\sum_{i=n+1}^{N} s_{i}\right)+R_{N} .
$$

На основі цього рівняння 3 врахуванням відповідних виразів для індексації або валоризації внесків отримуємо розміри всіх повних внесків $R_{n}$ базового кредиту. Повні внески $R_{n}^{(w)}$ валютного кредиту задовольняють рівняння еквівалентності капіталу

$$
W_{0}\left(1+\sum_{n=0}^{N} s_{n}^{(w)}\right)=\sum_{n=1}^{N-1} R_{n}^{(w)}\left(1+\sum_{i=n+1}^{N} s_{i}^{(w)}\right)+R_{N}^{(w)} .
$$

на основі якого знаходимо розміри цих внесків. Еквівалентну процентну ставку валютного кредиту знаходимо як розв'язок рівняння $V_{0}(1+y N)=\sum_{n=1}^{N} Z_{n}[1+y(N-n)]$.

У випадку складного нарахування процентів iз змінною ставкою розміри процентних ставок є різними для всіх термінів сплати внесків. Як i у випадку простого нарахування процентів позначимо через $s_{n}$ процентну ставку за $n-\breve{и}$ термін $\left(s_{n} \neq\right.$ const, $\left.\forall n=0, \ldots, N\right)$. Рівняння еквівалентності капіталу для базового кредиту, віднесене до кінця терміну сплати цього кредиту, можна записати у вигляді

$$
P_{0} \prod_{n=1}^{N}\left(1+s_{n}\right)=\sum_{n=1}^{N-1}\left[R_{n} \cdot \prod_{i=n+1}^{N}\left(1+s_{i}\right)\right]+R_{N} .
$$

На основі останньої системи рівнянь 3 врахуванням відповідних виразів для індексації чи валоризації внесків отримуємо розміри всіх повних внесків $R_{n}$ базового кредиту в національній валюті. Розміри повних внесків $R_{n}^{(w)}$ валютного кредиту шукаємо на основі рівняння, віднесеного до кінця сплати валютного кредиту

$$
W_{0} \prod_{n=1}^{N}\left(1+s_{n}^{(w)}\right)=\sum_{n=1}^{N-1}\left[R_{n}^{(w)} \cdot \prod_{i=n+1}^{N}\left(1+s_{n}^{(w)}\right)\right]+R_{N}^{(w)} .
$$

3 врахуванням виразів для індексації чи валоризації знаходимо відповідні повні внески валютного кредиту. Еквівалентну процентну ставку валютного кредиту знаходимо як розв'язок рівняння

$$
V_{0}(1+y)^{N}=\sum_{n=1}^{N}\left[Z_{n} \cdot(1+y)^{N-n}\right]+Z_{N} .
$$

\section{ВИСНОВкИ.}

Описані математичні моделі консолідації кредитів, сплачуваних у повних внесках, описують фінансові процеси об'єднання кількох кредитів в один і дають можливість знаходити розміри внесків цього нового кредиту. Такі моделі враховують різноманітні способи нарахування процентів (простий чи складний), а також просту чи змінну процентні ставки, як для кредитів у національній валюті, так і для валютних кредитів. Створений математичний апарат дає можливість порівнювати кошти кредитів перед консолідацією та після неї, знаходити умови надання кредитів, які забезпечують їх мінімальний кошт.

\section{СПИСОК ВИКОРИСТАНОЇ ЛІТЕРАТУРИ}

1. Кредитний ризик комериійного банку / В.В.Вітлінський, О.В.Пернарівський, Я.С.Наконечний, Г.І.Великоіваненко; За ред. В.В.Вітлінського.- Київ: Знання, 2000.- 251 с.

2. Марецька Е. Інформачійні моделі консолідації кредитів.- Львів: ДНДІІ, 2001.- 219 с.

3. Марецьька Е. Інформачійно-аналітична система супроводу кредитної діяльності // Вісник Східноукраӥнського національного університету.- 2001.- № 3 (37).- С. 152-160.

4. Марецька Е. Математичні моделі прочесів консолідації кредитів сплачуваних у капіталових внесках // Вестник Национального технического университета «Харьковский политехнический институт».- 2001.№ 8.- C. 84-92.

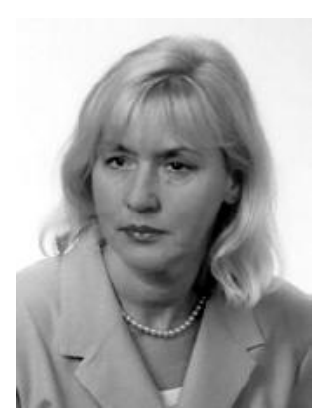

Марецька Ельжбета. Народилася в 1947 рочі. Закінчила Політехнічний інститут м.Лодзь (Польща). Кандидат технічних наук з 2000 року (дисертацію захистила в Державному науково-дослідному інституті інформаційної інфра- структури, м.Львів). Профресор Академії інформатики та управління м.Бєльсько-Бяла (Польща) та старший науковий співробітник Державного НДІ інформаційної інфраструктури. Наукові інтереси: математичне моделювання і прогнозування складних інформаційно-фінансових процесів. Автор 6 монографій та понад 70 наукових праць. 